\title{
Randomized controlled trials in ophthalmology: a bibliometric
}

\section{study [version 1; peer review: 2 approved]}

\section{Saif Aldeen AlRyalat (iD), Areen Abukahel, Khaled Ali Elubous (iD)}

Department of Ophthalmology, University of Jordan, Amman, Jordan

V1 First published: 04 Oct 2019, 8:1718

https://doi.org/10.12688/f1000research.20673.1

Latest published: 04 Oct 2019, 8:1718

https://doi.org/10.12688/f1000research.20673.1

\section{Abstract}

Background: Randomized controlled trials (RCTs) are situated at the top of hierarchy of evidence-based medicine, where its number and quality are important in the assessment of quality of evidence in a medical field. In this study, we aim to assess the status of RCTs in Ophthalmology.

Methods: On 15 th of May 2019, we performed a PubMed search for randomized controlled trials published in the field of ophthalmology using relevant filters and search terms. We categorized the results into specific topics in ophthalmology according to Medical Subject Heading (MeSH) database classification system. We used Altmetric explorer to identify journals and articles with the highest number of RCTs and highest citations.

Results: We found a total of 540,427 publications in the field of ophthalmology, of which only $11,634(2.15 \%)$ of them were RCTs. 'Retinal diseases' was the topic with the highest number of RCTs, followed by 'glaucoma' and 'conjunctival diseases'. The trial with highest number of citations was on retinal diseases. Only around 18\% of all ophthalmology RCTs are published in the top 10 ophthalmology journals, with a maximum percentage of RCTs was (5.53\%) published in Ophthalmology.

Conclusion: RCTs in ophthalmology primarily concern the retina, glaucoma, and a few other sub-topics, with little focus on sclera, orbit, and the eyelids. Most of the high impact RCTs are published in nonophthalmology journals.

Keywords Ophthalmology; Randomized Controlled Trials; PubMed; Retina; Journals; Bibliometrics.

\section{Open Peer Review \\ Approval Status \\ 1 \\ 2 \\ version 1 \\ 04 Oct 2019

$\checkmark$

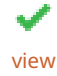 \\ 1. Peter Y Chang ID, Massachusetts Eye Research \& Surgery Institution (MERSI), Waltham, USA \\ 2. Sa'ed H. Zyoud AD, An-Najah National University, Nablus, Palestinian Territory Any reports and responses or comments on the article can be found at the end of the article.}


Corresponding author: Saif Aldeen AlRyalat (saifryalat@yahoo.com)

Author roles: AIRyalat SA: Conceptualization, Data Curation, Formal Analysis, Methodology, Supervision, Visualization, Writing - Review \& Editing; Abukahel A: Methodology, Resources, Writing - Original Draft Preparation; Elubous KA: Methodology, Resources, Writing Original Draft Preparation

Competing interests: No competing interests were disclosed.

Grant information: The author(s) declared that no grants were involved in supporting this work.

Copyright: @ 2019 AlRyalat SA et al. This is an open access article distributed under the terms of the Creative Commons Attribution License, which permits unrestricted use, distribution, and reproduction in any medium, provided the original work is properly cited.

How to cite this article: AIRyalat SA, Abukahel A and Elubous KA. Randomized controlled trials in ophthalmology: a bibliometric study [version 1; peer review: 2 approved] F1000Research 2019, 8:1718 https://doi.org/10.12688/f1000research.20673.1

First published: 04 Oct 2019, 8:1718 https://doi.org/10.12688/f1000research.20673.1 


\section{Introduction}

Since the conception of the term "evidence-based medicine" in clinical practice in $1992^{1}$, where well-conducted randomized controlled trials (RCTs) are situated at the top of hierarchy of evidence, there has been an emphasis on accepting high quality evidence in terms of RCTs in clinical practice. Moreover, previous reports showed that RCTs have generally higher methodological rigor than observational studies ${ }^{2}$. However, despite the rapid growth in ophthalmology literature in the recent years, this growth has not been paralleled by a growth in the quality of evidence ${ }^{3}$. This is evident by the number of Cochrane reviews that don't include any RCTs (i.e. empty review), which were estimated to be half of the total reviews on Cochrane Eyes and Vision in 2013. In this study, we aim to assess the status of RCTs in ophthalmology, and will focus on publishing trends for RCTs in ophthalmology in the recent years with regards to different ophthalmology topics.

\section{Methods}

PubMed search strategy

On $15^{\text {th }}$ of May 2019, we performed a PubMed search for randomized controlled trials published in the field of ophthalmology. We used the following search filters:

- Ophthalmology studies: eye diseases [MeSH Terms]

- RCT: Randomized Controlled Trial [Publication Type]

To categorize the results into specific topics in ophthalmology, we used the Medical Subject Heading (MeSH) database to identify the topics within ophthalmology, where the following were included:

\section{- Orbital Diseases}

- Conjunctival Diseases

- Corneal Diseases

- Eyelid Diseases

- Lacrimal Apparatus Diseases

- Lens Diseases

- Glaucoma

- Refractive Errors

- Scleral Diseases

- Uveal Diseases

- Retinal Diseases

For each topic, we added the query as a MeSH term to the search to identify relevant articles (e.g. Orbital diseases[Mesh Terms]. It is worth noting that trials might be categorized in more than one topic.

To identify journals with the highest number of RCTs and top articles with highest citations, we used Altmetric database, where we inputted the PubMed query we used in the PubMed search in the search field; the database yielded citation information about searched articles along with information about the journals these articles published previously ${ }^{5}$.

\section{Variables}

For each RCT, we extracted data regarding the topic of the study and categorized them into the following: RCTs per year, percentage of each sub-specialty, Articles per sub-specialty per year, Top 10 journals with their respective data, Top 10 articles with highest dimensions citations

\section{Results}

Ophthalmology RCTs

A total of 540,427 publications in the field of ophthalmology were identified, of which only 11,634 (2.15\%) of them were RCTs. There was a total of 482,791 RCT identified in all disciplines, of which only $2.4 \%$ are in the field of ophthalmology. Of these trials, 124 were phase 1 trials, 270 were phase 2 trials, 380 were phase 3 trials, and 42 phase 4 trials; all others did not have phases. Number of RCTs peaked in 2015 with a total of 583 trials. Figure 1 shows the trend in number of RCTs in the field of ophthalmology.

\section{RCTs in each ophthalmology topic}

'Retinal diseases' is the topic with the highest number of RCTs, with a total of 2915 trials, followed by 'glaucoma', with 2118 trials, and 'conjunctival diseases', with 1230 trials. Figure 2 details the number of trials for each topic.

Top RCTs and ophthalmology journals publishing RCTs The trial with highest number of citations discussed retinal complications of diabetes mellitus entitled "The Effect of Intensive Treatment of Diabetes on the Development and Progression of Long-Term Complications in Insulin-Dependent Diabetes Mellitus", published in The New England Journal of Medicine ${ }^{6}$. Table 1 details the top 10 RCTs with highest citations. A total of 2090 (18\%) of the RCTs were published in 10 journals, with "Ophthalmology" being the top journal with highest number of RCT published in it (643 RCTs). Table 2 details the top 10 journals with highest number of RCTs published in them.

\section{Discussion}

In the current study, we observed a peak in the annual number of RCTs on 2015, after which a steady decrease observed till 2018. Retinal diseases is the topic with the highest number of RCTs, followed by glaucoma and conjunctival diseases. The trial with highest citation was on retinal diseases and was published in The New England Journal of Medicine, where also other top cited trials were published in general non-ophthalmology journals. The total RCTs published in top 100 ophthalmology journals was only 2090 (17.96\%).

In general, there has been an increase in the number of RCTs in ophthalmology since the late 1990s. In a study assessing the frequency of prospective studies published in the American Journal of Ophthalmology and British Journal of Ophthalmology, 


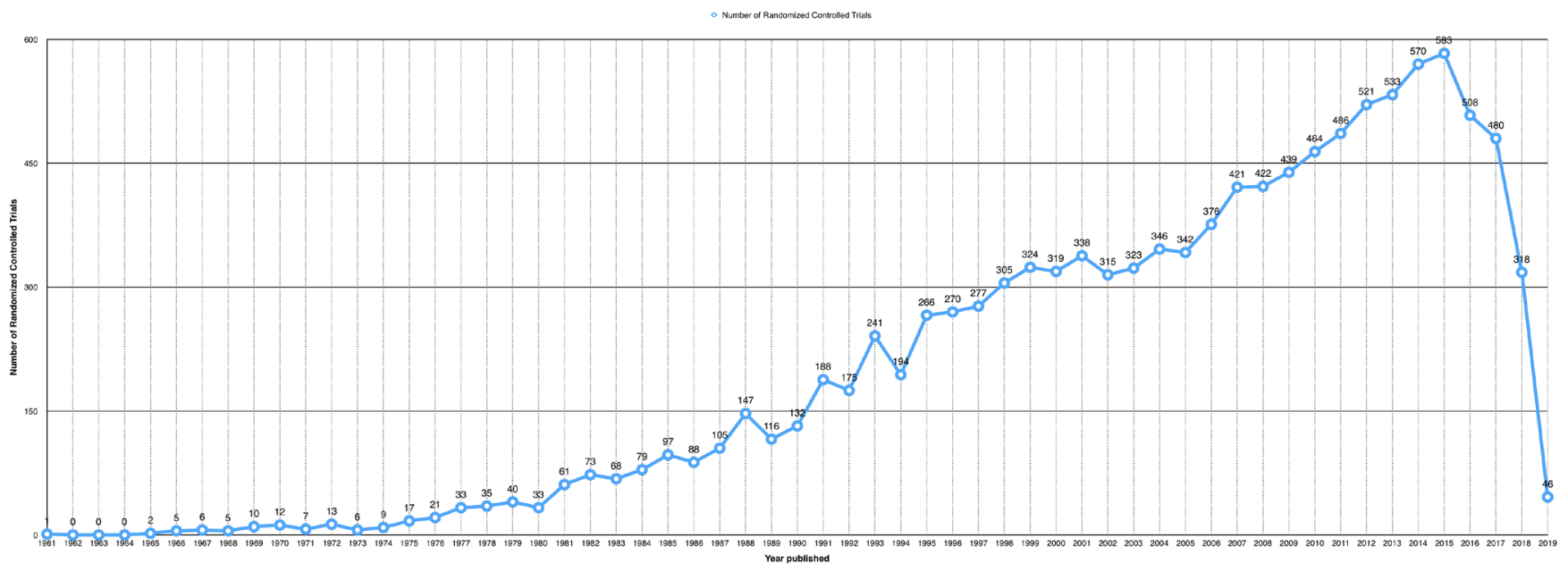

Figure 1. Number of randomized controlled trials published per year in the field of ophthalmology from 1961 to May 2019.

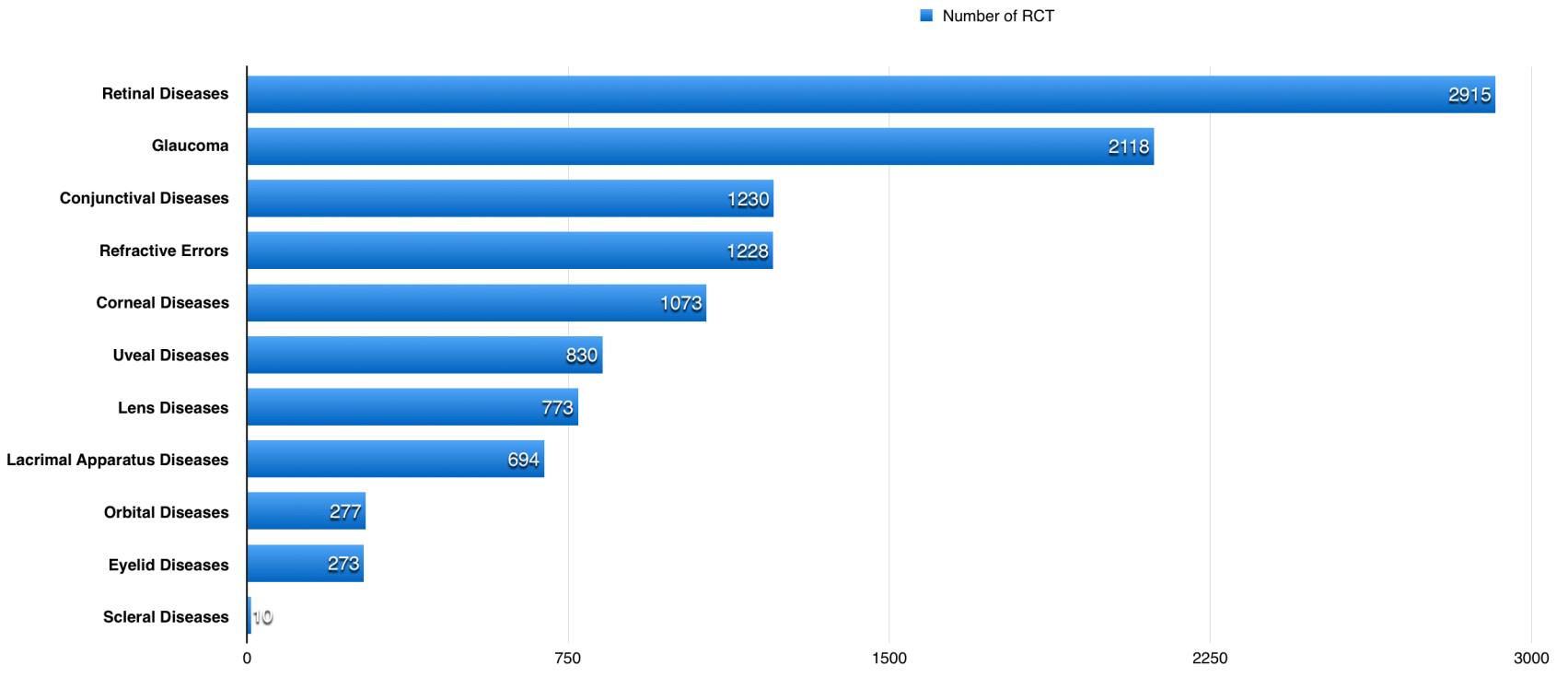

Figure 2. The number of randomized controlled trials (RCTs) for each topic in ophthalmology.

they found an increase from $1 \%$ to $12 \%$ during the years 1980 to $1999^{7}$. We observed a low number of RCTs among the ophthalmology literature, a percentage that didn't exceed $2.5 \%$ of the overall ophthalmology literature. In a previous study assessing the frequency of RCTs published in the major four ophthalmology journals, they found that only around $3.5 \%$ of their annual publications are RCTS ${ }^{8}$. Moreover, we found that only around $18 \%$ of all ophthalmology RCTs are published in the top 10 ophthalmology journals, with the most RCTs (5.53\%) published in Ophthalmology. In a study that reviewed risk of bias in RCTs published in major ophthalmology journals found that a risk of bias was observed in $29.4 \%$ of published $\mathrm{RCTs}^{9}$. In another study that assessed fragility of RCT's that included the comparison between two groups found a high proportion of fragile results in ophthalmology RCTs $^{10}$. In a study that assessed types of articles published in core pediatric journals, they found that only $0.3 \%$ were $\mathrm{RCTs}^{11}$, which supports our findings that a large proportion of RCTs were published in high-impact general medical journals.

One of the main limitations in this study is that it didn't assess the quality of RCTs, so we included RCTs from our 
Table 1. The 10 randomized controlled trials with the highest number of citations.

\begin{tabular}{|c|c|c|c|c|c|c|}
\hline Number & Citations & Title & Journal & $\begin{array}{l}\text { Publication } \\
\text { Date }\end{array}$ & Reference & OA Status \\
\hline 1 & 16741 & $\begin{array}{l}\text { The Effect of Intensive Treatment of Diabetes on } \\
\text { the Development and Progression of Long-Term } \\
\text { Complications in Insulin-Dependent Diabetes } \\
\text { Mellitus }\end{array}$ & $\begin{array}{l}\text { New England Journal } \\
\text { of Medicine }\end{array}$ & 1993 & 6 & FALSE \\
\hline 2 & 5177 & $\begin{array}{l}\text { Tight blood pressure control and risk } \\
\text { of macrovascular and microvascular } \\
\text { complications in type } 2+\text { diabetes: UKPDS } 38^{12}\end{array}$ & $\begin{array}{l}\text { British Medical } \\
\text { Journal }\end{array}$ & 1998 & 12 & TRUE \\
\hline 3 & 3623 & $\begin{array}{l}\text { Ranibizumab for Neovascular Age-Related } \\
\text { Macular Degeneration }\end{array}$ & $\begin{array}{l}\text { New England Journal } \\
\text { of Medicine }\end{array}$ & 2006 & 13 & FALSE \\
\hline 4 & 2343 & $\begin{array}{l}\text { Ranibizumab versus Verteporfin for } \\
\text { Neovascular Age-Related Macular } \\
\text { Degeneration }\end{array}$ & $\begin{array}{l}\text { New England Journal } \\
\text { of Medicine }\end{array}$ & 2006 & 14 & FALSE \\
\hline 5 & 2239 & The Ocular Hypertension Treatment Study & $\begin{array}{l}\text { Archives of } \\
\text { Ophthalmology }\end{array}$ & 2002 & 15 & TRUE \\
\hline 6 & 1736 & $\begin{array}{l}\text { Pegaptanib for Neovascular Age-Related } \\
\text { Macular Degeneration }\end{array}$ & $\begin{array}{l}\text { New England Journal } \\
\text { of Medicine }\end{array}$ & 2004 & 16 & TRUE \\
\hline 7 & 1683 & $\begin{array}{l}\text { The advanced glaucoma intervention study } \\
\text { (AGIS): } 7 \text {. the relationship between control } \\
\text { of intraocular pressure and visual field } \\
\text { deterioration }\end{array}$ & $\begin{array}{l}\text { American Journal of } \\
\text { Ophthalmology }\end{array}$ & 2000 & 17 & FALSE \\
\hline 8 & 1641 & The Ocular Hypertension Treatment Study & $\begin{array}{l}\text { Archives of } \\
\text { Ophthalmology }\end{array}$ & 2002 & 18 & TRUE \\
\hline 9 & 1640 & $\begin{array}{l}\text { Whole-Body Hypothermia for Neonates with } \\
\text { Hypoxic-Ischemic Encephalopathy }\end{array}$ & $\begin{array}{l}\text { New England Journal } \\
\text { of Medicine }\end{array}$ & 2005 & 19 & FALSE \\
\hline 10 & 1526 & $\begin{array}{l}\text { Grading Diabetic Retinopathy from } \\
\text { Stereoscopic Color Fundus Photographs } \\
\text { - An Extension of the Modified Airlie House } \\
\text { Classification }\end{array}$ & Ophthalmology & 1991 & 20 & FALSE \\
\hline
\end{tabular}

OA, open access.

Table 2. The 10 ophthalmology journals with the highest number of randomized controlled trials (RCTs) and proportion of RCTs of total ophthalmology RCTs published in each.

\begin{tabular}{|c|c|c|}
\hline Journal & Number of RCTs & $\begin{array}{c}\text { Percentage from total } \\
\text { ophthalmology RCT }\end{array}$ \\
\hline Ophthalmology & 643 & $5.53 \%$ \\
\hline American Journal of Ophthalmology & 333 & $2.86 \%$ \\
\hline British Journal of Ophthalmology & 246 & $2.11 \%$ \\
\hline Investigative Ophthalmology \& Visual Science & 163 & $1.40 \%$ \\
\hline Archives of Ophthalmology & 157 & $1.35 \%$ \\
\hline Journal of Cataract \& Refractive Surgery & 149 & $1.28 \%$ \\
\hline Retina & 106 & $0.91 \%$ \\
\hline JAMA Ophthalmology & 103 & $0.89 \%$ \\
\hline Optometry and Vision Science & 97 & $0.83 \%$ \\
\hline Journal of Glaucoma & 93 & $0.80 \%$ \\
\hline Total & 2090 & $17.96 \%$ \\
\hline
\end{tabular}


PubMed search regardless of their quality. Recent studies have stated that ophthalmology literature is of questionable methodological robustness, where RCTs become the center of the scope when methodological robustness is assessed, as they are the source of the highest level of evidence ${ }^{10,21}$. Future studies should focus on assessing quality of RCTs rather than the quantity (which was the scope of this study), where the Cochrane Eyes and Vision library criteria for RCT robustness can be utilized ${ }^{22}$.

\section{Data availability}

Underlying data

Harvard Dataverse: Ophthalmology randomized controlled trials. https://doi.org/10.7910/DVN/TXEYDX ${ }^{23}$.

This project contains the articles identified during this study.

Data are available under the terms of the Creative Commons Zero "No rights reserved" data waiver (CCO 1.0 Public domain dedication).
1. Evidence-Based Medicine Working Group: Evidence-based medicine. A new approach to teaching the practice of medicine. JAMA. 1992; 268(17): 2420-5. PubMed Abstract | Publisher Full Text

2. Lai TY, Leung GM, Wong VW, et al:: How evidence-based are publications in clinical ophthalmic journals?. Invest Ophthalmol Vis Sci. 2006; 47(5): 1831-8. PubMed Abstract | Publisher Full Text

3. Boudry C, Baudouin C, Mouriaux F: International publication trends in dry eye disease research: A bibliometric analysis. Ocul Surf. 2018; 16(1): 173-9. PubMed Abstract | Publisher Full Text

4. Wormald R, Dickersin K, Cochrane E, et al.: Evidence-Based Ophthalmology. Ophthalmology. 2013; 120(12): 2361-2363.e1.

PubMed Abstract | Publisher Full Text

5. Priem J, Groth P, Taraborelli D: The altmetrics collection. PLoS One. 2012; 7(11): e48753.

PubMed Abstract | Publisher Full Text | Free Full Text

6. Diabetes Control and Complications Trial Research Group, Nathan DM, Genuth S, et al:: The effect of intensive treatment of diabetes on the development and progression of long-term complications in insulindependent diabetes mellitus. N Engl J Med. 1993; 329(14): 977-86. PubMed Abstract | Publisher Full Text

7. Ang A, Tong L, Bhan A: Analysis of publication trends in two internationally renowned ophthalmology journals. Br J Ophthalmol. 2001; 85(12): 1497-8. PubMed Abstract | Publisher Full Text | Free Full Text

8. Bojikian KD, Gupta D, Dettori JM, et al:: Evidence in ophthalmology: Are we doing better? Ophthalmology. 2015; 122(12): 2584-6. PubMed Abstract | Publisher Full Text

9. Joksimovic L, Koucheki R, Popovic M, et al.: Risk of bias assessment of randomised controlled trials in high-impact ophthalmology journals and general medical journals: a systematic review. Br J Ophthalmol. 2017; 101(10): 1309-14.

PubMed Abstract | Publisher Full Text

10. Shen C, Shamsudeen I, Farrokhyar F, et al.: Fragility of results in ophthalmology randomized controlled trials: a systematic review. Ophthalmology. 2018; 125(5): 642-8.

PubMed Abstract | Publisher Full Text

11. Hardin WD Jr, Stylianos S, Lally KP: Evidence-based practice in pediatric surgery. J Pediatr Surg. 1999; 34(5): 908-13; discussion 912-3. PubMed Abstract | Publisher Full Text

12. UK Prospective Diabetes Study Group: Tight blood pressure control and risk of macrovascular and microvascular complications in type 2 diabetes: UKPDS 38. UK Prospective Diabetes Study Group. BMJ 1998; 317(7160): 703-13. PubMed Abstract | Free Full Text
13. Rosenfeld PJ, Brown DM, Heier JS, et al:: Ranibizumab for neovascular agerelated macular degeneration. $N$ Engl J Med. 2006; 355(14): 1419-31. PubMed Abstract | Publisher Full Text

14. Brown DM, Kaiser PK, Michels M, et al:: Ranibizumab versus verteporfin for neovascular age-related macular degeneration. N Engl J Med. 2006; 355(14): 1432-44. PubMed Abstract | Publisher Full Text

15. Kass MA, Heuer DK, Higginbotham EJ, et al:: The Ocular Hypertension Treatment Study: a randomized trial determines that topical ocular hypotensive medication delays or prevents the onset of primary open-angle glaucoma. Arch Ophthalmol. 2002; 120(6): 701-13. PubMed Abstract | Publisher Full Text

16. Gragoudas ES, Adamis AP, Cunningham ET Jr, et al:: Pegaptanib for neovascular age-related macular degeneration. N Engl J Med. 2004; 351(27): 2805-16. PubMed Abstract | Publisher Full Text

17. Agis Investigators: The Advanced Glaucoma Intervention Study (AGIS): 7. The relationship between control of intraocular pressure and visual field deterioration.The AGIS Investigators. Am J Ophthalmol. 2000; 130(4): 429-40. PubMed Abstract | Publisher Full Text

18. Gordon MO, Beiser JA, Brandt JD, et al: The Ocular Hypertension Treatment Study: baseline factors that predict the onset of primary open-angle glaucoma. Arch Ophthalmol. 2002; 120(6): 714-20. PubMed Abstract | Publisher Full Text

19. Shankaran S, Laptook AR, Ehrenkranz RA, et al:: Whole-body hypothermia for neonates with hypoxic-ischemic encephalopathy. N Engl J Med. 2005; 353(15): 1574-84.

PubMed Abstract | Publisher Full Text

20. Early Treatment Diabetic Retinopathy Study Research Group: Grading diabetic retinopathy from stereoscopic color fundus photographs--an extension of the modified Airlie House classification. ETDRS report number 10. Early Treatment Diabetic Retinopathy Study Research Group. Ophthalmology. 1991; 98(5 Suppl): 786-806.

PubMed Abstract | Publisher Full Text

21. Sanfilippo PG, Casson RJ, Yazar S, et al:: Review of null hypothesis significance testing in the ophthalmic literature: are most 'significant' $P$ values false positives? Clin Exp Ophthalmol. 2016; 44(1): 52-61. PubMed Abstract | Publisher Full Text

22. Higgins JP, Green S, editors: Cochrane handbook for systematic reviews of interventions. John Wiley \& Sons; 2011. Reference Source

23. AIRyalat SA: "Ophthalmology randomized controlled trials". Harvard Dataverse, V1. 2019 http://www.doi.org/10.7910/DVN/TXEYDX 


\section{Open Peer Review}

\section{Current Peer Review Status:}

\section{Version 1}

Reviewer Report 08 April 2020

https://doi.org/10.5256/f1000research.22737.r61423

(C) 2020 Zyoud S. This is an open access peer review report distributed under the terms of the Creative Commons Attribution License, which permits unrestricted use, distribution, and reproduction in any medium, provided the original work is properly cited.

\section{Sa'ed H. Zyoud}

Department of Clinical and Community Pharmacy, College of Medicine and Health Sciences, AnNajah National University, Nablus, Palestinian Territory

I would like to congratulate you on the work done. This helps to analyze the most active researchers in the subject, facilitating future collaborations. I would like to ask some questions that were not very clear for me in the paper.

1. Why did you only use PubMed to survey data?

2. How did you consider collaborations?

3. You could have done more interesting things, such as a heat map (VOSViewer has a great one and is free to use - but have used it in a previous bibliometric analysis).

4. Bibliometric is an aid in the characterization of a field, but scholarly communication is too complex to explain the history, status, and development of any field of science. Bibliometric has a lot of limitations that should be recognized in order to avoid a simplistic misuse of the indicators and methodologies.

Borgman, C. L., and Furner, J. (2002). Scholarly communication and bibliometrics. Annu. Rev. Inform. Sci. Technol. 36, 3-72. doi:10.1002/aris.1440360102

Hicks, D., Wouters, P., Waltman, L., Rijcke, S. D., and Rafols, I. (2015). Bibliometrics: the Leiden Manifesto for research metrics. Nature 520, 429-431. ${ }^{2}$

Without further comments or questions, I congratulate again the initiative.

\section{References}

1. Borgman C, Furner J: Scholarly communication and bibliometrics. Annual Review of Information Science and Technology. 2005; 36 (1): 2-72 Publisher Full Text

2. Hicks D, Wouters P, Waltman L, de Rijcke S, et al.: Bibliometrics: The Leiden Manifesto for 
research metrics.Nature. 2015; 520 (7548): 429-31 PubMed Abstract | Publisher Full Text

Is the work clearly and accurately presented and does it cite the current literature? Yes

Is the study design appropriate and is the work technically sound?

Yes

Are sufficient details of methods and analysis provided to allow replication by others? Yes

If applicable, is the statistical analysis and its interpretation appropriate? Yes

Are all the source data underlying the results available to ensure full reproducibility? Yes

Are the conclusions drawn adequately supported by the results?

Yes

Competing Interests: No competing interests were disclosed.

Reviewer Expertise: Toxicology, bibliometric

I confirm that I have read this submission and believe that I have an appropriate level of expertise to confirm that it is of an acceptable scientific standard.

Reviewer Report 21 October 2019

https://doi.org/10.5256/f1000research.22737.r54690

(C) 2019 Chang P. This is an open access peer review report distributed under the terms of the Creative Commons Attribution License, which permits unrestricted use, distribution, and reproduction in any medium, provided the original work is properly cited.

\section{Peter Y Chang}

Massachusetts Eye Research \& Surgery Institution (MERSI), Waltham, MA, USA

I applaud the authors' efforts in sifting through the large volume of data in determining the proportion of ophthlamology publications that are cateogorized as RCTs. The authors also found that most of the RCTs concern retinal diseases. This makes sense, as one of the most dramatic therapeutic advancements since early 2000s- not just in Ophthalmology but all of medicine - is the employment of anti-VEGF therapy in the treatment of age-related macular degeneration and diabetic retinopathy. These two conditions, along with glaucoma, are perhaps the 3 most common ophthalmic conditions for which many newer therapeutics are being developed. It is also encouraging to see that the number of RCT published annually in Ophthalmology has generally 
trended upward, and that they are published in well-regarded peer-reviewed journals. Overall, though, there remains a lack of RCTs in Ophthalmology, with majority of published works being presumably retrospective in nature.

Is the work clearly and accurately presented and does it cite the current literature? Yes

Is the study design appropriate and is the work technically sound?

Yes

Are sufficient details of methods and analysis provided to allow replication by others? Yes

If applicable, is the statistical analysis and its interpretation appropriate? Yes

Are all the source data underlying the results available to ensure full reproducibility? Yes

Are the conclusions drawn adequately supported by the results? Yes

Competing Interests: No competing interests were disclosed.

Reviewer Expertise: Ocular inflammatory diseases, vitreoretinal surgery

I confirm that I have read this submission and believe that I have an appropriate level of expertise to confirm that it is of an acceptable scientific standard.

The benefits of publishing with F1000Research:

- Your article is published within days, with no editorial bias

- You can publish traditional articles, null/negative results, case reports, data notes and more

- The peer review process is transparent and collaborative

- Your article is indexed in PubMed after passing peer review

- Dedicated customer support at every stage

For pre-submission enquiries, contact research@f1000.com 